This item was submitted to Loughborough's Research Repository by the author.

Items in Figshare are protected by copyright, with all rights reserved, unless otherwise indicated.

\title{
Understanding construction reform discourses
}

PLEASE CITE THE PUBLISHED VERSION

http://dx.doi.org/10.1080/01446193.2014.909049

\section{PUBLISHER}

(C) Taylor \& Francis

\section{VERSION}

AM (Accepted Manuscript)

\section{PUBLISHER STATEMENT}

This work is made available according to the conditions of the Creative Commons Attribution-NonCommercialNoDerivatives 4.0 International (CC BY-NC-ND 4.0) licence. Full details of this licence are available at: https://creativecommons.org/licenses/by-nc-nd/4.0/

\section{LICENCE}

CC BY-NC-ND 4.0

\section{REPOSITORY RECORD}

Smiley, John-Paul, Scott Fernie, and Andrew R.J. Dainty. 2019. "Understanding Construction Reform Discourses". figshare. https://hdl.handle.net/2134/17693. 


\section{Understanding Construction Reform Discourses}

\section{ABSTRACT}

Attempts to drive change and reform of the UK construction industry have been an ongoing concern for numerous stakeholders, both in government and across industry, for years. The issue is a seemingly perennially topical one which shows little sign of abating. Scholarly analyses of the reform agenda have tended to adopt a Critical Theory perspective. Such an approach, however, lacks a certain nuance and perhaps only reveals one layer of social reality. What is arguably lacking is a more fundamental exposition concerning the historical, social and cultural explanatory forces at play. Whilst it is illuminating to expose vested interests, ideology and power, what has led to the development of various views? How have they come to achieve such high accord in discussions? Drawing on the works of Max Weber, Georg Simmel and Barbara Adam, this paper seeks to develop a broader theoretical lens. It considers the wider sociocultural structures and forces that influence behaviour, shape and constrain these views. This approach will contribute to a much needed broader philosophical and theoretical debate within the Construction Management community (and beyond) on the need to better engage with, and understand, the sources influencing the issue of policy formulation and diffusion.

Keywords: Culture, Discourse, Policy, Reform, Time 


\section{INTRODUCTION}

From the offices people work in, the schools they learn in, to the homes they live in, no one escapes the influence of the built environment and, hence, the construction industry which creates and maintains it. Perhaps because of this fact, no other industry has come under as much public scrutiny and the examination has not been a favourable one, with the construction sector continuously suffering from poor word of mouth and negative public image problems (Ball: 1988). Complaints of spiralling costs, unexpected delays, poor workmanship and dangerous working practices abound, leading some researchers to ask the question, 'Why is construction so backward?' (Woudhuysen and Abley: 2004). Consequently, discourses articulating the need for change and reform of the UK construction industry have been an ongoing concern for a multitude of stakeholders, both in government and industry alike, for years (Fernie et al: 2006). Although debates concerning the need for reform have been especially prevalent in the UK, construction sector 'crises' are apparent in most countries (Koskela et al: 2003: p. 1). The issue is a seemingly perennially topical one which shows little sign of abating. Concern regarding the construction sector is far from a modern issue though. As Morton (2008) points out, there have been calls for reform from the 1800s onwards, with a letter to the Editor of The Builder in 1847 complaining about the tendering process for a London housing development (Morton: 2008: p. 8). Considering the essential necessity of the built environment to human existence and societal development, there is little doubt that debates concerning its nature and purpose stretch back somewhat further than that.

Relatively recent discourse(s) concerning change and reform include the Latham (1994) and Egan (1998) reports, the 'Technology Foresight Report' (1995), 'Modernising Construction' (2001), 'Accelerating Change' (2002) and the Wolstenhome report 'Never Waste a Good Crisis' (2009). These have, as Cahill and Puyberand (2003: p. 150) observed whilst reviewing the Latham report, been '... warmly supported by all political parties throughout the country'. However, the reasons for such a wide consensus across the political spectrum are rarely 
examined, leaving a range of unanswered questions about the reform discourse, its provenance and effects. Arguably, this consensus may rest upon more fundamental underlying cultural predispositions. If so, does this matter? What are the implications of such a consensus on the development and diffusion of reforms? Furthermore, what will an understanding of consensus and cultural predispositions expose about power relations, vested interests, taken-for-granted norms, values, assumptions and cultural attitudes within the context of developing and diffusing reform? And, by extension, the construction industry, its structure and those who work in it? Without a more thorough and reflexive understanding of this consensus and potential cultural predispositions, answers to these questions and the potential to reconceptualise practice are limited.

A theoretical and analytical lens which couples Critical Theory to a broader socio-historical cultural perspective will be argued in this paper to provide a thorough and reflexive basis to understand consensus, cultural predispositions and to lay the foundations for addressing the questions above. What are presented in the paper are arguments to support the development of the lens by broadly examining the assumptions and limitations of research driven by, and responding to, reform discourse via: Partnering and Building Information Modelling (BIM). These have been chosen as they provide concrete examples of both a long-established and relatively recent reform discourse. In doing so, arguments for a more thorough and robust theoretical lens to deepen our understanding of the shape of reform discourse(s), as well as attempts to reform practice, are developed. It is suggested that a particular combination of biology and cultural forces has led to an increasingly homogenous discourse surrounding construction reform and several key cultural events are identified. It is argued that only through a realisation of our constraints will the potential to reimagine the built environment become possible. To further sharpen and support these arguments, a consideration of ontological security and, that spectre of social science, Weber's (1904) 'Iron Cage', are presented. The 
conclusions of the paper draw together these arguments and form the basis for positioning a new theoretical and analytical lens within the previous and contemporary calls for theoretical development and maturity in project and construction management research (Seymour et al: 1997, Reich et al: 2013). It is hoped that such an approach will be of assistance to academics, policymakers and professionals alike.

\section{PARTNERING}

The discourses surrounding partnering offer an interesting theoretical departure point for developing the lens. It is a discourse with a long history and one which is now firmly entrenched in Construction Management circles and thinking. Partnering (or 'alliancing' or 'collaborative' approaches - see Bresnen and Marshall: 2000) has been suggested as a more collaborative way of working which brings a multitude of perceived benefits to all parties involved. These potential 'benefits' include increased productivity, reductions in project costs and times and a reduction in industry fragmentation and the perceived, pejoratively, adversarial culture in the industry (Bresnen: 2007). Partnering, in a sense then, could perhaps be considered as mimicking the actions of symbiotic relationships in the natural world, where organisms cooperate for mutual benefit. Of course, whether they are truly mutually beneficial or instead characterised by commensalism or parasitism, such cooperative relationships are often the best means of survival for smaller organisms in a hostile and cut-throat world. Bresnen and Marshall (2000) and Bresnen (2007) problematise the issue of partnering though and highlight the dearth of more sophisticated theoretical approaches to the topic. They call to attention not only the contested definitional and conceptual nature of partnering but also the role of power, inequality and vested interests (both between and within organizations) which shape how partnering develops in practice. Whilst examining power will provide useful insights into partnering at both the individual and organisational levels, a wider cultural perspective combined with a critical approach is arguably needed to offer a more complete picture. This would provide greater 
insight into how and why values of reduced time, lower costs, increased speed and narrow views of efficiency have come to dominate reform discourse. It would also help to explain how such values have come to be privileged and desirable cultural virtues.

Arguably, with its calls for long-term relationships, stability and expectations of fidelity, the rhetoric of partnering also mirrors wider societal norms and values and calls for stable relationships that provide healthy, productive, stable lives. As with any marriage, there is potential for conflict and disagreement and, '...the prospect of a shared destiny means also the need for mutual accommodation and compromise, with an all-out war as the only - unpalatable - alternative' (Bauman: 2003: p. 13). This vision, however, can be contrasted with the increasing liquidity and fluid nature (which some might pejoratively label as promiscuous) of interpersonal relationships in modern life, (see Bauman: 2000, for example). From this perspective, calls for partnering are arguably conservative endeavours, reflecting societal norms which seek to maintain or perhaps reintroduce prevailing traditional societal norms and values and bring a modicum of morality to business practices within the sector. Or, perhaps more cynically, partnering could be characterised as marriages of convenience, based solely on desires for financial security and stability. Without a more critical eye on wider societal norms and values and how they shape, depart from, reflect or reinforce calls for partnering, it is problematic to make sense of its promotion and diffusion via reform discourses and initiatives.

Notably, turning a more critical eye to the issue of partnering, Gottlieb and Jensen (2012) use a discursive institutionalism theory perspective to examine the rise of partnering discourse in Denmark. They suggest that, '...partnering is conceptualized as a destabilization of an existing institutional terrain rather than as institutionalization of a new project governance practice...' (Gottlieb and Jensen: 2012: p. 160). Whilst such a study is valuable, there is the potential to build upon it through a more explicit examination of the role, and contested nature, of power, 
inequalities, and vested interests in the development, stabilization and continuation of institutions and their role in reform. Indeed, whilst this research perspective identifies the role of ideals in the formation of institutions, it is limited in exploring whose ideas take precedence, how they may be formed and why these particular ideas (in competition with others) at this particular point in time. To provide insights into these issues, research that combines Critical Theory with a socio-historical cultural lens offers a way to complement and inform the work of those turning a critical eye on reform discourse and initiatives.

The work of Gottlieb and Jensen (2012) and others apart, research into partnering continues to be dominated by a prescriptive flavour, with little in the way of nuanced, critical, reflexive examinations of the issue (Bresnen: 2007). Ongoing debates and discussion in the project and construction management literature addressing the role of history, power, culture and the metaphysical assumptions and theory upon which policy and practice rest are limited. There is little debate for example on how and why partnering (discourse and practice) was initially formulated, by whom, or on what basis power (whose voice carries the most weight) shaped its development and diffusion. Debates concerning the ontological and epistemological assumptions which form the bedrock of such policies are also sparse within the literature. There are notable limitations and gaps in the project and construction management literature concerning partnering and by extension, reform discourse and initiatives. Arguably debates need to be extended and guided by alternative theoretical and analytical lenses. Whilst partnering as a discourse has longevity, what of a reform discourse that is new; such as BIM?

\section{BIM}

Forming a central plank of the Government's Construction Strategy (2011) and Industrial Strategy (2013), BIM is both novel and central to UK industry reform discourse and practice. Though BIM is currently much hyped and heralded, the promise of technology has long been 
challenged by researchers. Earlier work by Suchman (1994), for example, problematised the increasingly uncritical acceptance of ICT and suggested that, 'Computer technology, the directionality and dynamics of change, and the forms of work that are the objects of change are treated as self-evident... and naturalized entities' (Suchman: 1994: p. 187). More recently, researchers with a critical eye have begun in earnest to explore the underlying technological determinism and assumptions of BIM discourse. For example, Davies and Harty (2012) explore issues of control, surveillance and power and expose an assumption held by researchers that diffusion is considered to be largely, '...unproblematic technical activities...positioned as politically neutral and generally beneficial...' (Davies and Harty: 2012: p. 24). These assumptions and the prescriptions that follow are argued to be too readily accepted by a multitude of stakeholders without due thought or critical examination. Whilst exposing uncritical acceptance of discourse, such research does not expose or explain the cultural predispositions of those with vested interests in adopting particular assumptions. If developing and diffusing BIM discourse and practice cannot be assumed to be a neutral, value free technological prescription, then an understanding of the norms and social relations in the particular cultural milieu in which BIM has emerged is fundamental. Indeed, how has the prescription referred to as BIM come to be seen as a 'rational' course of action and why has it emerged at this particular time, as opposed to others? It is also necessary to question why it has been so 'persuasive' to so many and why are 'control' and 'surveillance' deemed necessary and desirable components in construction projects? Perhaps more importantly, one might question, to what end? It is important to recognise that BIM has emerged in response to a perceived need, driven by concerns over issues of productivity, efficiency and value, but this 'need' is itself predicated on socio-historically specific value-laden assumptions regarding what constitutes 'good' practice.

The variance in perceptions between those of different cultural backgrounds and its potential to disrupt BIM implementation is also rarely discussed, though an understanding of such would 
seem important in an increasingly globalised world where companies have ever diverse workforces. There are potentially significant practical and ethical implications for working practices enshrined within the BIM agenda. Practical failure to apply such an approach is arguably likely to result in perceived inefficiencies. More importantly, however, there is an ethical concern regarding the imposing of a singular, abstract working pattern on individuals whose cultural expectations of work may be different than others involved. Such a realisation also helps to further highlight issues of power differentials and inequality. Whilst undoubtedly challenging to remedy, there must be serious doubts as to the extent to which an employer can be said to be showing respect for employees if they do not take such considerations into account. Summerfield and Lowe (2012) make the point concerning culture and BIM, that,

'...the international development of BIM software will undoubtedly need reworking in order to address the local conditions of a nation... Context remains such a powerful determinant of outcome in and for the built environment that much of the research effort must necessarily remain local, geographically, culturally and politically...' (Summerfield and Lowe: 2012: p. 393).

That is not to suggest that culture itself is the sole determiner of context, there are, of course, technical and geographical differences and constraints which influence the development of respective built environments. But, as shall be seen shortly, there are reasons to believe that we can increasingly expect to see more similarities than differences.

To further and deepen our critical understanding of BIM, it is also interesting to consider the role of time and its absence from much literature and discussion. Though it is briefly alluded to in terms of reducing time (which interestingly has come to be linked historically with 'efficiency'), time is an all too often taken for granted aspect of culture. It is often reified and treated as an 
unalterable, objective aspect of our reality. The differences, for example, between the uniform, commodified, decontextualized nature of the time inherent in BIM and other ICT that employers attempt to impose on their workforce and the variable, contextualised nature of time as humans experience it are rarely explored (Adam: 1995; Chan: 2012). Humans perceive time at a variety of different tempos and rhythms depending on a variety of factors, for example, stress levels, emotional state and cultural background. Such a qualitative and contextual dimension of time is neglected in the majority of debates and discussion within the literature concerning BIM. As Adam et al (2002) suggest,

'Difficulties clearly arise when the invariable measure is imposed as the norm on highly context-dependent, rhythmic, and variable situations and processes... for example, we know that not all working time is the same: night-time is different from daytime, weekends and festive days are different from weekdays. The idea of working 'unsocial hours' acknowledges that there are significant differences in the apparently neutral working hours...' (Adam et al: 2002: p. 12).

That such a narrow, singular perception of time has come to be predominant and that an arguably increasingly homogenous discourse surrounding construction 'improvements' is emerging worldwide is a point that shall be developed later on. But the need to examine issues of power becomes apparent, then, when we consider disputes between employers and employees over the 'value' of their respective times. An understanding of how actors come to hold values can be achieved by research that engages with and explores the social milieu in which they emerge and the social norms, values and roles prevalent at the time. Concepts such as 'social' and 'unsocial' hours, for example, are only intelligible by exploring the broader social context. What is needed is a description and knowledge of the primordial soup from which various cognitive frames and discourses emerge, without which an understanding of said discourses, values, attitudes and behaviours cannot be complete. To more fully understand the development of 
partnering and of BIM and other ICT prescriptions, and their relationship with and impact upon human thought and behaviours, we need a genealogy of power, history and culture.

\section{POWER, HISTORY, AND CULTURE - AN INSEPARABLE MIXTURE}

Drawing inspiration from the Frankfurt School and Critical Theorists such as Horkheimer, Adorno, and Habermas, a Critical Theory approach to organization and management research has sought to, '...interrogate and challenge received wisdom about management theory and practice' (Alvesson and Willmott: 2003: p. 1). Recognising the necessity of querying varying frameworks and hierarchies of power, particularly as found in capitalist societies, such critical work has helped to problematise established norms and, in doing so, has raised numerous ethical concerns. Its desire to highlight inequalities and offer an emancipatory dimension to scholarly analysis is an essential remedy to the somewhat dry and detached nature of much scholarship today. But, whilst a Critical Theory perspective has helped shine a light on the importance of ideology, vested interests and power struggles arguably inherent in construction reform discourse and initiatives, the approach, by itself, is limited in its explanatory potential, lacks a certain nuance and perhaps only reveals one particular layer of social reality present. That various social actors in competition for scarce resources vie with each other for power and control only reveals a partial insight. It is, to an extent, stating the obvious. The use of dialectical thinking, so common to a Critical approach, whilst potentially illuminating is arguably over simplistic and rests upon a hidden teleology that cannot be assumed. As Lawson (2006) notes, 'Ideology and institutionalised social practices are important, but alone merely represent the locally mediated expression of underlying networks of social relations' (Lawson: 2006: p. 21). Moreover, as has been shown in relation to critical project studies, the focus of dialectic thinking on closed syntheses of binary oppositions has the potential to result in the unreflective generation of new concepts (Sage et al: 2009). A critical perspective also arguably rests on an unwarranted view of human nature, one which makes of central importance the presence of competitive urges and 
conflict at the expense of other, differing conceptions, for example, that of mutual aid and cooperation (Kropotkin: 1902). Furthermore, it neglects that the various actors involved, even dominant ones, are themselves humans influenced and shaped by the prevailing discourses and social milieu of their times. After all, how is it determined that someone represents a 'powerful' or 'dominant' actor in the first place? And why do the powerful seek the particular interests they do, as opposed to others? Critical Theory, then, offers a valuable piece of the puzzle, so to speak, but only a piece; it is limited in providing insight as to bow and why the behaviours, vested interests and power struggles have come to exist in the first place, or why they have come to take the particular shape and forms that they currently do, as opposed to possible alternatives.

Arguably, what is needed is a more fundamental exposition concerning the historical, social and cultural explanatory forces at play (Hempel: 1942). Whilst it is illuminating to expose vested interests, ideology and power, what led to the development of such views? How have they come to achieve such high accord in discussions? Why have some discourses emerged at the expense of others? Why have some lasted through successive reports, whilst others have faded from the agenda? Whilst some scholars (for example, McCabe: 2007, who traces the historical developments which influenced the current 'Respect for People' agenda) have recognised the importance of history in the formation of current trends and policy recommendations, there is still little discussion of the wider cultural and ideological dimensions at work. For, whilst efficiency, rationality and the desire for speed have come to dominate discourses regarding change and reform, it is important to recognise that idealizing and prioritizing said characteristics is a socio-historical temporally specific cultural construct. That is, it is specific to a particular time and space/place in human history and is the result of human artifice. It has not always been this way and need not always be in the future.

A subtle but important point has been touched upon by Green (2011) who states, 
'The people who work in construction are the same people with whom we all socialise every weekend. They have the same strengths and the same weaknesses; they have varying levels of education and they possess the same diversity of political opinion as can be found within the broader society within which they are embedded' (Green: 2011: p. xiii).

It is the latter part of this quotation which is of importance here. Construction sector actors are not an island to themselves but are subjects who are embedded in a particular historical period and influenced by the prevailing socio-cultural milieu of their times. The built environment, and the methods used to create it, reflect and embody the history, norms, values, social relations and level of development of the society in which they exist. As Marx so eloquently reminded us,

'Men make their own history, but they do not make it just as they please; they do not make it under circumstances chosen by themselves, but under circumstances directly encountered, given and transmitted from the past. The tradition of all the dead generations weighs like a nightmare on the brain of the living' (Marx: 1852/1970: p. 15 in Ritzer and Goodman: 2003: p. 44).

So, an appreciation, in this instance, of reform discourse and practice in the UK construction industry must move beyond Critical Theory perspectives to consider more broadly, the sociohistorical cultural factors and forces which have led us to this particular point.

\section{ONTOLOGICAL SECURITY}

Green (2011) suggests that managers and those in charge of reform and improvement specifically choose prescriptions and that, '...recipes are used as sense making mechanisms...' which '...support practitioners sense of self-identity...' (Green: 2011: p. 321). That is, they will choose recipes and recommendations which resonate most clearly with their ontological 
perspectives, thus providing greater ontological security for said practitioners. Ontological security can be described as a secure cognitive state arising from and sustained by a perceived sense of continuity in the actor's natural and social worlds (for more on ontological security see Laing: 1960 and Giddens: 1991). From this perspective then, actors involved in the development and diffusion of reform discourse and initiatives choose reforms which buttress and support their already existing world-view. We can arguably expect a significant amount of consensus between varying cultural actors regarding 'appropriate' conditions for ontological security. As Blackford (2006) points out, the necessary,

'...conditions are shaped not only by culture but also by our evolved biology and the physical world that we all live in. Thus, we can expect a great deal of intercultural agreement about the background conditions to human choice' (Blackford: 2006: p. 7).

The extent to which the world that we inhabit can be moulded for ourselves is shaped and influenced by the limitations and contemporary realities of the human body, hence the study of Ergonomics and the design of the buildings and objects we use. Working practices are limited and shaped by the nature of human embodiment and the inherent frailties of the human body which necessitate technological innovations as compensation. As humans, by and large, possess similar physical bodies and inhabit similar physical planes, the potential for plasticity in any users cognitive experience is thus limited. Our shared biology provides a foundation and constraining framework within which cultures and practices can potentially emerge.

This perspective allows for the realisation that the various social actors involved actively (consciously or not) produce and reproduce certain realities. It is a way of maintaining a particular social order and is intimately entwined with the actor's visions of self and identity. This has important, practical consequences for social actors involved in the development and diffusion of industry reforms, as, 
'...control over their personal agendas is limited...by the political, economic and social structures that generate opportunities for choices and decisions, and by their own awareness of their opportunities for exercising influence in any of these spheres' (Dahl: 1991: p. 25).

So, choices and decisions are constrained by the particular institutional arrangements prevalent at any given time. This realisation helps to shed light on how and why said world-views may come to be formed in the first place. It also helps to address why it is that one particular measure rather than another competing view or recipe lends itself to the buttressing of an individuals' ontological security at a particular socio-historical juncture. But there is still a question as to what has led us to this point. For even if we have an account of the meanings, motives and practices of individuals or groups we do not necessarily have a story of their origins or of any subsequent changes or developments. For example, what of the historical and social forces that have shaped living arrangements and the built environment, with the traditional trend almost universally observed of the nuclear family and/or extended kin relations inhabiting a communal built space? Why this configuration as opposed to others? And what of the fact that such social relations have remained the norm over time and the resulting impact this has had on exchange relations commerce, patterns of production and consumption? It is essential to consider issues such as these, as,

'Buildings result from social needs and accommodate a variety of functions - economic, social, political, religious and cultural. Their size, appearance, location and form are governed not simply by physical factors (climate, materials or topography) but by a society's ideas, its forms of economic and social organisation, its distribution of resources and authority, its activities, and the beliefs and values which prevail at any one period of time' (King: 1980: p. 1). 
And these ideas, beliefs and values are themselves products whose emergence has been determined, to some extent, by a particular combination of biology, history and culture. However, discussion concerning determinism in existing critical perspectives on reform runs contrary to this view. For example, Green et al (2008) highlight how 'competitiveness' is more appropriately considered as a discourse which derives its legitimacy from neoliberal thought and the 'enterprise culture'. Green et al appear reluctant, however, to adopt a more deterministic position, in which a discourse actively shapes and contributes to an agent's views and behaviours, and speak of the need to avoid the '...trap of determinism..' (Green et al: 2008: p. 433). Likewise, Gottlieb and Haugbølle (2013) when considering the issue of partnering state, '... change is unpredictable and non-deterministic...' (Gottlieb and Haugbølle: 2013: p. 123). Such approaches, though, arguably rest on an overly generous account of human agency. An explication of determinism, perhaps framed in terms of evolutionary biology and socio-biology could possibly prove fruitful here. For example, a recent study (Brembs: 2010) has suggested a genetic basis for 'free will' and argues that humans are not unlike other animals in this regard in that we are constrained by our biology regarding the choices open to us. It suggests that although, '...behaviour can be unpredictable, responses do seem to come from a fixed list of options' (Palmer: 2010: p. 9). The study is interesting as it suggests that it is partly the biology of our brains that shapes and constrains what we perceive to be our options. Such an idea is not new though and was anticipated by previous thinkers, such as Popper, who stated that, '...we are born with expectations: with knowledge which,...is psychologically or genetically a priori i.e. prior to all observational experience...' (Popper in Hollis: 1994: p. 74), and W. O. Quine, who believed that, '...the answer might lie in the biology of the brain and our human constitution: we are, so to speak, hard-wired to construe experience... as we do' (Hollis: 1994: p. 83). Could it not be considered, then, that an individual's psychological predictions, habits and preferences are, at least in part, a causal result of cultural forces? Or that they are mutually constitutive forces which 
interact with, shape, and constrain each other against a backdrop of biology and culture which limits the potential variety and plasticity of any user experiences?

If the biology of the brain and sense organs influences our ability and potential to store, process and retrieve information, then an understanding of it becomes important for any discussions concerning norms, values, interests and how they impact on behavioural patterns. Such considerations are important when we recognise, '...built environments as physical expressions of schemata and cognitive domains: environments are thought before they are built (Rapoport in King: 1980: p. 284 - emphasis in original). And the development of such thoughts is influenced by a combination of biological, cultural and environmental factors. This biological consideration provides a much needed missing element from debates and research in construction management, and complements work provided by Gottlieb and Haugbølle (2013). This is not meant to crudely reduce culture to biology. Rather it suggests that an appreciation of the complex tapestry of biology and culture and its influence is necessary if culture based studies are to provide real impact in either academic or professional circles. No understanding of power or culture is complete without a consideration of corporeality and its ramifications. A chain, after all, is only as strong as its weakest link.

Returning to the issue of partnering once again, it is essential, as Bresnen (2007) points out, to see the importance of more fully understanding mental processes and the factors influencing their formation: '...the development and success of partnering is seen as dependent upon many intangible and elusive cognitive and social aspects, such as attitudes, motivations, openness and trust' (Bresnen: 2007: p. 366 - emphasis added). A realisation of this helps in gaining a more intricate and nuanced understanding of the various factors which contribute to, and impact upon, the cognitive processes and assumptions which underpin policy and practice.

From a postmodernist perspective, actors involved in any policy process must be considered as, '..."already embedded practitioners" whose standards of judgements, canons of evidence, or 
normative measures are proscribed by his or her professional community' (Danziger: 1995: p. 435). And this, of course, applies to academics as well as those involved in policy (or academics involved in policy making directly). That is to say that even well meaning, so-called reflexive researchers and practitioners are actors who are shaped, at least to some extent, by the prevailing social milieu of their times. There is no escaping this as, even if some self-aware, reflexive practitioner appreciates this and attempts to adopt some neutral position, such a stance (cherishing neutrality) is itself a value. Thus, the development and diffusion of reform discourse and initiatives cannot be considered as an objective matter but rather, as an inter-subjective endeavour, one which is characterised by the social process of negotiation between actors with differing goals, values and motivations. In fact, the very formulation of such policy debates is, '...defined by the values of the society. Growing out of value conflict, they represent efforts to reformulate the world and bring it closer to what is desired' (Greer: 1961 cited in Bynner and Stribley: 1979: p. 49). An understanding of the social zeitgeist and of the norms and values which guide practitioners, as well as the role of power and the contested nature of practice, is essential. A more holistic appreciation of the development of norms, values and the culture which influences and constrains the thoughts and actions of policymakers is important, with a more reflexive understanding offering the potential to reimagine practice. Hence the need for a novel theoretical and analytical lens framed by and extending Critical Theory to provide desperately needed fresh insights into reform and policy development in construction. This lens however needs to consider the factors which have led to the current cultural social zeitgeist and the resulting cognitive predispositions. To do so, it is necessary to revisit that spectre of social science, the 'iron cage'.

\section{THE 'IRON CAGE REVISITED’, AGAIN}

Thirty years ago, DiMaggio and Powell (1983) wrote of the increasingly homogenous nature of organizational discourse and sought to, '...explain homogeneity, not variation' (DiMaggio and 
Powell: 1983: p. 148). Thirty years on and arguably the march towards increasing homogenisation has continued with the uncritical acceptance of various prescriptions underpinned by an emphasis on 'efficiency', 'value' and 'productivity'. Such characteristics, as Ness and Green (2012) have commented, '...have become naturalised; they are seen as commonsense by all or almost all the participants and thus not seen as ideological or as representing the position of those with most power' (Ness and Green: 2012: in Dainty and Loosemore [eds] p. 25). But how has this come to be the case? An appreciation of this subject only becomes more visible through a more thorough, critical examination with biology, history, culture and the social. It is especially interesting to consider the roles of Weber, Simmel and Adam. For although it is essential to consider discourse, rhetoric and the power relations enshrined in them, there is little insight into the way said relations come about. A tentative theoretical premise then will be that the development of a papered moneyed economy (Simmel: 1907), along with the standardization and decontextualization of time from the 1800 s onwards (Adam) have led to an increasing predominance of instrumental rationality at the expense of other competing forms of rationality (Simmel: 1903 and Weber: 1904). As Chan (2012) points out, this more nuanced appreciation of time is all too often missing from construction management literature, including discussions concerning partnering and BIM. Yet,

'It is this narrow perspective of time, which results in the relative neglect of the qualitative experiences associated with moving through (and in) time that add to a more holistic comprehension to how individuals working in the industry construct a sense of time. It is only through this rounded understanding that one could potentially find the clues to unlock the puzzle of the performance of time in projects' (Chan: 2012: p. 498).

This predisposition has, in turn, been spread globally through a combination of both the diffusion of new technologies and the collapsing of space and time that said new information 
technologies has afforded (Castells: 2004) and by the spread of neoliberalism thought and practices by the leading actors of our times. In fact, the discourse referred to as 'Neoliberalism' could only arguably have come about as a result of the above combination of forces and events. Critically, the varied combination of processes commonly referred to as 'globalisation' can themselves be considered as, '... an ideological assertion rather than a description of inevitable economic and cultural processes' (Faulks: 1999: p. 70). This particular combination of events, like a slow-setting cement mixture, has gradually began to harden, with discourses surrounding construction 'improvements' becoming ever more intractable, unmoveable, and unimaginative as a result.

The political philosopher Michael Oakeshott, himself a staunch critic of the turn to Rationalism, stated,

'But what, at first sight, is remarkable, is that politics should have been earlier and more fully engulfed by the tidal wave [of rationalism] than any other human activity. The hold of Rationalism upon most departments of life has varied in its firmness...but in politics it has steadily increased and is stronger now than at any earlier time' (Oakeshott in Callahan: 2008: p. 26).

It is through the socio-historical theoretical lens stated above that we may arguably hope to begin to make sense of the ever increasing tendency for this particular type of rational thought to dominate policy development, construction debates and, indeed, everyday contemporary existence. The potential for humans to cognitively perceive differing perspectives is constrained by a particular combination of biological, historical and cultural forces. In this context, it is not so remarkable that this specific type of instrumental rationality would begin to be privileged over other, competing forms of knowledge, for, as Simmel (1903) stated, 
'Money economy and the dominance of the intellect are intrinsically connected...it reduces all quality and individuality to the question: How much? All intimate emotional relations between persons are founded in their in individuality. Whereas in rational relations man is reckoned with like a number...' (Simmel: 1903: p. 3).

The abstract, impersonal nature of money (particularly papered money) alters social and exchange relations, impacts psychological frames and, combined with the advent in 1913 of 'Global time', with the first wireless time-signal sent from the Eiffel Tower, and the increasing decontextualisation and commodification of time (Adam: 1995), has meant the stripping of, '...both work and time from their contextual meanings...' (Adam: 1990: p. 116). This has led to an increasing predisposition to an instrumental means-end rationality that prioritizes the efficient maximization of monetary gains at the expense of other competing values. In industrial life, this can be seen clearly in prescriptions such as Taylorism and Fordism, which embody such ideals. Adam (1995), using the example of Taylorism, suggests that,

'It exemplifies the monetary attitude to time as something that needs to be spent and allocated with scientific precision. Every second of the worker's time has to be used to its fullest potential...members of industrial societies have been socialised into treating time like money, in other words, not to waste and squander it' (Adam: 1995: p. 113).

This cultural predisposition, spread and perpetuated by the dominant wealth possessors of our times, has become our very own 'Iron Cage'. That is, a dominant rationality and cultural intellectual discourse so engrained due to the socialisation process that many social actors (intellectuals and lay-persons alike) have difficulty even imagining 'viable' alternatives. To borrow a turn of phrase from the economist J. K. Galbraith (1958), a new 'conventional wisdom' is born. This has led to a situation where, 'Each individual's opportunity to create and develop becomes 
increasingly restricted by intellectualization, rationalization (including the sphere of law), and the “calculating exactness" of modern times' (Capetillo-Ponce: 2005: p. 117). Notions of 'Best practice', then, must be seen as reflective of and linked to more fundamental philosophical assumptions regarding what actors conceive to be the 'Good life'. And these visions of the 'Good life' have not emerged in a vacuum but are the result of a combination of cultural, historical and biological factors.

An appreciation of this helps to place into context the repeated emphases by those calling for reform and change in construction on value for money (for both business and clients alike) in successive reports ranging from Banwell through to Latham and Egan and the National Audit Office's (2004) Getting V alue for Money from Construction Projects Through Design. This is a sentiment so stubbornly entrenched that the Royal Institute of Chartered Surveyors (RICS) recent (2013) publication simultaneously reports that, '...the Coalition Government...need to make efficiencies and reductions in the cost of the construction they procure', whilst proudly proclaiming their creation of a new standard which can, '...help reduce spending on individual projects and allow for more projects to be delivered within restricted budgets' (RICS: 2013: p. 10). The more things change the more they seemingly stay the same! It also goes some way to explain the currently booming 'business of BIM' with a plethora of expensive workshops and courses increasingly being offered for this allegedly 'essential' prescription; arguably prioritizing money at the expense of workers' health (both mental and physical) and ability to balance life and work more generally. Interestingly, from a sociological perspective, we can link the calls for 'Respect for People' with the moral discourses surrounding 'clean' and 'dirty' money (Baker and Jimerson: 1992). Monies are inextricably embedded within the wider social milieu in which they emerge and how they are exchanged, distributed, and accumulated matters to the social actors involved, with debates reflecting the prevailing moral discourses prevalent at the time. So, 'Respect', in this context, is linked to both practices and remuneration which are perceived to be 
fair (however 'fair' is defined by the various actors involved). And debates, both within the Human Resource Management literature and illustrated in the actions of unions, fighting for perceived injustices and improvements in working conditions, must be considered as competing discourses which represent a negotiation of contemporary morality. But what has led to the emergence of these particular discourses in the first place? How have these specific moral sentiments amongst the various actors present evolved? It is important to ask such questions as a much needed corrective measure for a great deal of the academic and policy literature which does, '... not provide explicit reflection on the values or interests such 'policy implications' are meant to advance' (Bartram: 2010: p. 355). The emphasis on wealth creation and accumulation is, for example, but one ideal and approach which can potentially be used, there are alternatives.

These value assumptions are now so engrained that there is no real examination of the fundamental metaphysical, value and normative assumptions which lay at the heart of calls for reform, from academics or construction professionals alike. The latter can perhaps be excused but for the former, who supposedly profess critical thinking and reflexivity as virtues, it arguably constitutes a dereliction of duty. To their credit, Murray and Langford (2003) do hint at the need to more carefully consider these issues and the potential for an alternative in one of the book's final paragraphs, when they state that,

'...the features of performance improvement in the past have been decidedly driven by the concepts of wealth creation. The future could be driven by the creation of a better sense of well-being; less stress, more leisure, more harmonious professional relationships and, above all, a greater sense of fun and playfulness in our working lives' (Murray and Langford: 2003: p. 215). 


\section{CONCLUSIONS}

In the introduction to this paper, a question was posed concerning the role of an underlying cultural predisposition in the articulation of reform discourses. An attempt has been made to answer that question and it has been suggested that the standardization of time, combined with the rise of ICT and the money economy, has led to a historically specific cultural zeitgeist which shapes and constrains the thoughts and actions of contemporary social actors, leading to a particular type of ontological security. The implications of this, to answer an earlier question, do matter and they are profound. From the creators, who imagine and decide upon 'suitable' reform policy, to the blue-collar workers charged with implementing it, such a predisposition provides the ontological foundation of norms, values and assumptions which informs and shapes practice. This cultural zeitgeist, combined with the shared physical characteristics of social actors, helps to explain the increasingly homogenous nature of reform discourses. What is important to realise, though, is that in attempting to understand reform discourses, it is not enough to simply shine a light on inequalities, power differentials, and vested interests. Question of differentials of power, in all its forms, and the resulting social inequality should arguably be a major focus of any research agenda. But such an approach, though valuable and of great ethical importance, is incomplete. In attempting to understand the various calls for change and reform in construction, it is important to understand the numerous forces which have led to both past and current discourses. And this must include and consider seriously the delicate interplay between biology and environment and their combined impact on the perceptions and consciousness of the various social actors involved. By combining a Critical approach with a more fundamental sociohistorical cultural lens, a more detailed, nuanced and sophisticated understanding can be achieved. Future research in Construction Management, for example, should address not only issues of power but must consider historical and cultural dimensions. Comparative cross country studies, particularly longitudinal ones, could be extremely revealing in this regard, for example, and would allow researchers to understand more clearly how, when and why similarities and 
differences regarding policy emerged. Such research should also make explicit the normative and value assumptions behind calls for reform as well as the ontological and epistemological foundations inherent. There is arguably a moral imperative for us, as a community of researchers, to critically examine the genealogy of norms, values, attitudes, and behaviours, including our own. Why do we esteem certain values at the expense of others, how has this come to be the case historically? How have we arrived at the particular cultural milieu we currently experience? By even attempting to answer such questions, by fostering this sort of reflexive, hyper-critical attitude, assumptions and taken for granted attitudes can be revealed, challenged, and made transparent. An assessment of the constraints and influences on our thoughts offers the emancipatory potential necessary to reimagine the built environment. A more honest and humble debate, informed by knowledge of the sources and influences of various discourses is essential. Without such an effort, the unreflective majority will continue to aimlessly stumble on and even well-meaning critics will have difficulty finding inventive solutions to perceived problems. After all, attempts to think outside the box necessarily depend on the contours and characteristics of the box. But,

'Since such forces of life have grown into the roots and into the crown of the whole of the historical life in which we, in our fleeting existence, as a cell, belong only as a part, it is not our task either to accuse or to pardon, but only to understand' (Simmel: 1903: p. $10)$.

\section{REFERENCES}

Adam, B. (1990) Time \& Social Theory, Cambridge: Polity Press.

Adam, B. (1995) Timewatch: the social analysis of time, Cambridge: Polity Press.

Adam, B., Whipp, R. and Sabelis, I. (2002) 'Choreographing Time and Management: Traditions, Developments and Opportunities' in Whipp, R. Adam, B. and Sabelis, I. [eds] Making Time: Time and Management in Modern Organizations. Oxford: Oxford UP. 
Alvesson and Willmott [eds] (2003) Studying Management Critically, London: SAGE Publications.

Baker, W., and Jimerson, J. (1992) 'The Sociology of Money', American Behavioral Scientist, Vol. 35, No. 6, pp. $678-693$.

Ball, M. (1988) Rebuilding Construction: Economic Change in the British Construction Industry, London: Routledge Press.

Banwell, Sir Harold (1964) The Placing and Management of Contracts for Building and Civil Engineering Work. Her Majesty's Stationary Office, London.

Bartram, D. (2010) 'The normative foundations of 'policy implications': reflections on international labour migration', Work, Employment, Society, Vol. 24, No. 2. pp. 355 - 365.

Bauman, Z. (2000) Liquid Modernity, Cambridge: Polity Press.

Bauman, Z. (2003) City of Fears, City of Hopes, London: Goldsmiths College Publishing, University of London.

Blackford, R. (2006) 'Sinning against nature: the theory of background conditions', Journal of Medical Ethics, Vol. 32, pp. 629 - 634.

Brembs, B. (2010) 'Towards a scientific concept of free will as a biological trait: spontaneous action and decision-making in invertebrates', Proc. R. Soc. B, Published online before print December 15, 2010.

Bresnen, M. and Marshall, N. (2000) 'Partnering in construction: a critical review of issues, problems and dilemmas', Construction Management and Economics, Vol. 18, pp. 229 - 237.

Bresnen, M. (2007) 'Deconstructing partnering in project-based organisation: Seven pillars, seven paradoxes and seven deadly sins.' International Journal of Project Management, Vol. 25, No. 4, pp. 365 - 374.

Cahill, D and Puybaraud, M C 'Constructing the Team: The Latham Report' in Murray, M. and Langford, D. [eds] (2003) Construction Reports - 1944-98, pp. 145 - 160, Oxford: Blackwell Publishing.

Callahan, G. (2009) 'Michael Oakeshott on Rationalism in Politics', The Freeman-Ideas on Liberty, Vol. 59, No. 1, Foundation for Economic Education.

Capetillo-Ponce, J. (2004/5) 'Contrasting Simmel's and Marx's Ideas on Alienation', Human Architecture: Journal of the Sociology of Self-Knowledge, Vol. III, Nos. 1\&2, Fall 2004/Spring 2005.

Castells, M (2004) The Power of Identity, The Information Age: Economy, Society and Culture Vol II, Oxford: Wiley-Blackwell Publishing.

Chan (2012) 'Constructing a sense of time in projects: Implications of a Bergsonian view of time', In: Smith, S.D (Ed) Procs 28th Annual ARCOM Conference, 3-5 September 2012, Edinburgh, UK, Association of Researchers in Construction Management, pp. 497 - 507. 
Dahl, R. A., Modern Political Analysis - Fifth Edition, London: Prentice-Hall International Publishing.

Danziger, M. (1995) 'Policy Analysis Postmodernized: Some Political and Pedagogical Ramifications', Policy Studies Journal, Vol. 23, No. 3, pp. 435 - 450.

Davies, R and Harty, C (2012) Control, surveillance and the 'dark side' of BIM In: Smith, S.D (Ed) Procs 28th Annual ARCOM Conference, 3-5 September 2012, Edinburgh, UK, Association of Researchers in Construction Management, pp. 23 - 32.

DiMaggio, P. J., and Powell, W. W. (1983) 'The Iron Cage Revisited: Institutional Isomorphism and Collective Rationality in Organizational Fields', American Sociological Review, Vol. 48, No. 2, pp. $147-160$.

Egan, Sir John. (1998) Rethinking Construction. Report of the Construction Task Force to the Deputy Prime Minister, John Prescott, on the scope for improving the quality and efficiency of UK construction. Department of the Environment, Transport and the Regions, London.

Faulks, K. (1999) Political Sociology: A Critical Introduction, Edinburgh: Edinburgh University Press.

Fernie, S., Leiringer, R., and Thorpe, T. (2006) 'Rethinking change in construction: a critical perspective', Building Research and Information, Vol. 34, No. 2, pp. 91 - 103.

Galbraith, J. K. The Affluent Society, London: penguin Books Ltd.

Giddens (1991) Modernity and Self Identity: self and society in the late modern age, Cambridge: Polity Press.

Gottlieb, S. C., and Jensen, J.S. (2012) 'Making sense of partnering: discourse, governance and institutional change', Engineering Project Organization Journal, Vol. 2, No. 3, pp. 159 - 170.

Gottlieb, S. C., and Haugbølle, K. (2013) 'Contradictions and collaboration: partnering in-between systems of production, values and interests', Construction Management and Economics, Vol. 31, No. 2, pp. 119 - 134.

Green, S. D., Harty, C., Elmualim, A. A., Larsen, G. D., \& Kao, C. C. (2008). 'On the discourse of construction competitiveness', Building Research \& Information, Vol. 36, No. 5, pp. 426 435.

Green, S. D. (2011) Making Sense of Construction Improvement, Oxford: Wiley-Blackwell Publishing.

Greer, S. [1961] 'On the selection of problems' pp. 48 - 52 in J. Bynner and K. M. Stribley [eds], Social Research: Principles and Procedures, (1979), London: Longman Group Limited.

Hempel, C. G. (1942) 'The Function of General Laws in History', in Martin, M and McIntyre, L. [eds], Readings in the Philosophy of Social Science, London: MIT Press.

H M Government (2011) Government Construction Strategy, Report published by the Cabinet Office, May 2011. 
H M Government (2013) Construction 2025: industrial strategy for construction - government and industry in partnership, Report published by the Department for Business, Innovation \& Skills, July 2013.

Hollis, M. (1994) The philosophy of social science: An introduction, Cambridge: Cambridge University Press.

King, A. [ed] (1980) Buildings and Society - Essays on the social development of the built environment, London: Routledge and Kegan Paul Press.

Koskela, L., Ballard, G., \& Howell, G. (2003), 'Achieving change in construction', In Proceedings of the International Group of Lean Construction 11th Annual Conference (IGLC-11), pp. 22 - 24.

Kropotkin, P. (1902/1989) Mutual aid: a factor of evolution, Montreal: Black Rose Books.

Laing, R. D. (1960) The Divided Self: An Existential Study in Sanity and Madness, Harmondsworth: Penguin Books Ltd.

Latham, Sir Michael (1994) Constructing the Team. Final report of the Government/industry review of procurement and contractual arrangements in the UK construction industry. HMSO, London.

Lawson, J. (2006) Critical Realism and Housing Research, London: Routledge.

Morton, R. (2008) Construction UK - Introduction to the Industry, Oxford: Blackwell Publishing.

McCabe, S. (2007) 'Respect for people - The dawn of a new era or mere rhetoric?', in Dainty, A., Green, S. and Bagilhole, B. [eds] People and Culture in Construction - A Reader, London: Taylor and Francis Group.

Murray, M. and Langford, D. [eds] Construction Reports - 1944-98, Oxford: Blackwell Publishing.

National Audit Office (2001) Modernising Construction. Report by the Comptroller and Auditor General of the National Audit Office, The Stationary Office, London.

National Audit Office (2004) Getting V alue for Money from Construction Projects through Design. Report prepared by Davis, Langdon \& Everest, National Audit Office, London.

Ness, K and Green, S. D. (2012) 'Human resource management in the construction context: disappearing workers in the UK' in Dainty, A and Loosemore, M [eds] Human Resource Management in Construction - Critical Perspectives - $2^{\text {nd }}$ Edition (2012) pp. 18 - 50.

Office of Science and Technology (1995) Technology Foresight: Progress Through Partnership, London.

Palmer, J. (2010) 'Free Will Similar in Animals, Humans-But Not So Free', $16^{\text {th }}$ December 2010, bbc.in/1 fBHq5R, [accessed on the $12^{\text {th }}$ March 2014].

Rapoport, A. 'Vernacular architecture and the cultural determinants of form' in King, A. [ed] (1980) Buildings and Society - Essays on the social development of the built environment, pp. 283 - 305, London: Routledge and Kegan Paul Press. 
Reich, B.H., Liu L., Sauer, C., Bannerman, P., Cicmil, S., Cooke-Davies, T., Gemino, A., Hobbs, B., Maylor, H., Messikomer, C., Pasian, B., Semeniuk, M., and Thomas, J. (2013) 'Developing better theory about project organizations', International Journal of Project Management, Vol. 31, No. 7 , pp. 938 - 942.

Royal Institute of Chartered Surveyors (2013) RICS Construction Policy, Report prepared by the Royal Institute of Chartered Surveyors, March 2013, London.

Ritzer, G. and Goodman, D. J. (2003) Sociological Theory - Sixth Edition, London: McGraw Hill Publishing.

Sage, D.J., Dainty, A.R.J. and Brookes, N.J. (2010) 'A Consideration of Reflexive Practice within the Critical Projects Movement’, International Journal of Project Management, Vol. 28, No. 6, pp. 539 - 546.

Seymour, D., Crook, D. \& Rooke, J. (1997) 'The Role of Theory in Construction Management: A Call for Debate,' Construction Management and Economics, Vol. 15, No.1. pp. $117-119$.

Simmel, G. (1903) 'The Metropolis and Mental Life', Available online at: bit.ly/MeiHwF [accessed on the $20^{\text {th }}$ February 2014]

Simmel, G. (1907) The Philosophy of Money, Third Edition - Edited by David Frisby (2005), London: Routledge.

Strategic Forum (2002) Accelerating Change, Rethinking Construction, London.

Suchman, L. (1994) 'Do Categories Have Politics? The language/action perspective reconsidered', Computer Supported Cooperative Work, Vol. 2, pp. 177 - 190.

Summerfield, A.J., and Lowe, R (2012): Challenges and future directions for energy and buildings research, Building Research \& Information, Vol. 40, No. 4, pp. 391 - 400.

Weber, M (1904/2011) The Protestant Ethic and the Spirit of Capitalism, Oxford: Wiley-Blackwell Publishing.

Wolstenhome, A. (2009) Never Waste a Good Crisis, Constructing Excellence in the Built Environment, London.

Woudhuysen, J. and Abley, I. (2004) Why is construction so backward?, Chichester: Wily-Academy Publishing. 